\title{
Guide to Africa Bibliography
}

\section{Scope and coverage}

This bibliography records publications on Africa of interest to students of Africa, principally in the social and environmental sciences, development studies, humanities and arts. Some items from the medical, biological and natural sciences are included. The criterion used is potential relevance to a reader from a social sciences/arts background. The whole continent and associated islands are covered, with selective coverage of the diaspora. This volume aims to cover material published in 2018 together with items from earlier years not previously listed. The editor is always very glad to hear of any items omitted so that they may be included in future volumes. He would be particularly pleased to receive notification of new periodicals, print or online. African government publications and works of creative literature are not normally listed.

The principal sources of data for this volume are the holdings of SOAS University of London; the Afrika Studiecentrum, Leiden; and material received by the International African Institute. Much of this material, and especially chapters in edited books, has been personally examined by the editor. Additional data has been garnered from other published bibliographies, both print and online, from COPAC, the online union catalogue of the UK's major research libraries, and AJOL (African Journals Online - http://www.ajol.info/), which provides invaluable access to periodicals published in Africa.

\section{Arrangement}

The arrangement of the bibliography is by region and country, with a preliminary section for the continent as a whole. Each region or country begins with a General section and then subject fields (see below for list) follow in alphabetical order. Where an item might appear under more than one heading, this is indicated by cross-reference (see the 'see also' list immediately under each subject heading) or the subject index will guide users to it.

\section{Entry types}

The bibliography contains three types of entry: periodical articles, books and pamphlets, and chapters. Book entries give author, title, place, publisher and pagination (but not ISBN numbers or price). Entries for chapters in books that are largely not on African topics give full bibliographic information for the volume concerned. However, when a book contains many relevant chapters it is listed separately and the chapter entry includes only a short version of the title, the name(s) of the editor(s), and the entry number of the book itself. An increasing number of periodicals are published in online only formats and in these cases, the url is given.

\section{Indexes}

The bibliography has author and subject indexes, which use the entry number to identify relevant items. The first three authors only of multi-authored works are listed. Where an item is sufficiently described by the subject heading, it will not appear in the subject index. Users are advised to scan broadly. The index will be most useful for those searching under concepts such as Constitution or Structural Adjustment or under the names of ethnic groups and languages. It also makes some use of keywords, often reflecting the vocabulary of the original entry. 


\section{Subject headings}

Agriculture
Anthropology
Archaeology
Architecture
Archives
Arts
Bibliography
Biography
Botany
Current Affairs
Demography
Development
Diaspora and Migration
Economic and Social History
Economics
Education
Education - Higher
Environment
Exploration and Travel
Finance
Fisheries
Food
Forestry
Gender
Gender - Masculinity
Geography
Geology
Heritage and Museums
History
History, Early
History, C6-18th
History, C19th
History, C1900-1960
History, 1960-
History, South African War, 1899-1902
[under South Africa]

\section{Online edition}

Africa Bibliography is published simultaneously in print and online editions. The online edition is a fully searchable database of both the current volume and past volumes. The online version consolidates records collected from the bibliography's foundation in 1984 up to the current volume. The result is a rich and interactive resource for scholars interested in the study of Africa. With user-friendly search functionality and links straight to the full-text of articles or library catalogues, and full bibliography reference export tools to bibliographic managers, the online version enables researchers to locate references quickly. Free trials and further information may be found at http:// africabibliography.cambridge.org/.

An additional guide to the online version is available at http://africabibliography. cambridge.org/guideToBibliography.do.

\section{Language coverage}

The Africa Bibliography includes items in languages other than English; notably items in French, German, Afrikaans, Italian and Portuguese. Some volumes of Africa Bibliography also include selected items in Swahili. 